\title{
THE RELATION BETWEEN ENVIRONMENTAL STRESSORS AND SEVERITY OF THE CLINICAL PROFILE OF PSORIASIS IN AN EGYPTIAN SAMPLE
}

\author{
Eid, E. M. ${ }^{(1)}$; Swelem, Mervat, M. ${ }^{(2)}$; Sadek, H. A. ${ }^{(1)}$ \\ and Ismail, Azza, M. $^{(3)}$
}

1) Faculty of Medicine, Ain Shams University 2) Faculty of Medicine, El-Azhar University (Girls) 3) Ministry of Health

\begin{abstract}
Psychological stressors have been reported to precede the onset of psoriasis in $44 \%$ of patients, initiate recurrent skin flares in $88 \%$ of psoriatic and may worsen psoriasis severity and may even lengthen the time to disease clearance.

This study aimed to: 1 . Identifying the types of stressors, which are related to the forms and severity of clinical profile of psoriasis, 2 . Identifying the types of psychosocial factors which are related to the forms and severity of clinical profile of psoriasis in Egyptian sample. Methods: One hundred and fifty patients randamised samples were collected from dermatological out-patient clinic affiliated to ministry of health and universities hospitals. All subjects were exposed to the followings: A full dermatological history including exacerbating factors. General examination to exclude chronic diseases. Clinical examination, Socioeconomic data will be collected for all patients. Holms and Rahe for assessment of stressors. Psoriasis area severity index.

Results: The socio-demographic characteristics show that the mean age of patients with psoriasis of both sexes was 40.91 (standard deviation, SD 14.26) years, while the men:women ration was 2.66:1. Additionally, $68 \%$ of psoriatic patient were occupationally skilled person; $18 \%$ were un-employed; $10 \%$ were professional and $4 \%$ were students. A significant relation between weather condition and type of
\end{abstract}


psoriasis severity was noticed. It appears that psoriatic patients were improved in summer and worsened in winter. During autumn and springs, patients didn't notice changes in psoriasis signs. A significant relation between presence of psychological stress and degree of psoriasis severity. It appears that moderate degree of psoriasis was the most common among psoriatic patient with stress (45.5\%) or without stress $(65.3 \%)$.

Conclusion: The study showed that environmental stressors have relevant effects on severity of psoriasis. In addition, there is a specific relation between both climate and psychological stresses on the severity of psoriasis.

Keywords: Environmental stressors, Psoriasis, Holms and Rahe, Psoriasis area severity index, Psychosocial factors, Psychological stressors, Weather.

\section{INTRODUCTION}

Stress has long been reported to trigger psoriasis (Arnold, 2005 \& 2007). High index of stressful life events associated with patients having more than double the risk of psoriasis compared to low scorers. However, the same study found that current and ex-smokers had approximately double the risk of psoriasis, Naldi et al. (2005).

Most patients who report episodes of psoriasis precipitated by stress describe disease-related stress, resulting from the cosmetic disfigurement and social stigma of psoriasis, rather than stressful major life events or nonspecific distress (Arnold, 2005 \& 2007).

The mechanism of stress-induced exacerbations of psoriasis has been speculated to involve the nervous, endocrine, and immune systems, but no definitive pathways have been established. A more direct connection may be the effects of anxiety or depressive symptoms 
in reducing the threshold for pruritus in psoriatic patients (Gupta et al., 1994).

Environmental risk factors include; trauma (Eyre and Krueger, 1982), infections (Tervaert \& Esseveld, 1970 and Telfer et al., 1992), drugs (Griffiths et al., 2010), sunlight (Ros and Eklund, 1987), the 3month postpartum period (Dunna and Finlay, 1989), social stress (Griffiths et al., 2010), seasonal variation and climate change (Bell et al., 1991), and smoking and alcohol (Griffiths et al., 2010).

In this study it was aimed to investigate the following stresses, tobacco smoking, alcohol and drug abuse, climate weather changes, and social stresses, to psoriasis profile and severity.

\section{AIMS OF THE STUDY}

\section{This study aimed at:}

1. Identifying the types of stressors, which are related to the forms and severity of clinical profile of psoriasis.

2. Identifying the types of psychosocial factors which are related to the forms and severity of clinical profile of psoriasis.

\section{SUBJECTS AND METHODS SUBJECTS}

A sample of 150 patients (old and new cases) has been collected from dermatological out-patient clinic affiliated to Ministry of Health and Universities Hospitals. 


\section{Inclusion Criteria:}

Age: above 18 years.

Sex: Both sexes were included in this study.

\section{Exclusion Criteria:}

1- Patients having chronic diseases associated with psoriasis.

2- Patients that may receive drugs that affect psychological conditions, except drug medications of psoriasis e.g. corticosteroids and methotrexate.

\section{METHODS}

\section{Procedures:}

All subjects were exposed to the followings:

1. Socioeconomic data will be collected for all patients.

2. A full dermatological history including exacerbating factors.

3. Holms and Rahe for assessment of stressors. It is a list of 43 stressful life events that can contribute to psychiatric illness. To measure stress according to Holmes and Rahe stress scale the number of life change units that apply to events in the past year of an individual life were added and the final score gave a rough estimate of how stress affect health.

4. General examination to exclude chronic diseases.

5. Clinical examination Grattage test and histopathology. Grattage test is to remove the scales by a glass slide to examine the pin point hage appearance of psoriasis. 
6. Psoriasis area severity index, it includes 4 parameters including itching, erythema, scaling and thickness. The severity parameters were measured on a scale of 0 to 4 from none to maximum.

\section{Design of Study:}

\section{Biphasic Study:}

Phase I: Descriptive study.

Phase II: Analytical study.

\section{Research Tools:}

1. The social Readjustment Rating Scale, Holms and Rahe for assessment of stressors (Okasha et al., 1981), and 2. Psoriasis area severity index (PASI) (Kreft et al., 2006).

\section{Statistics:}

Data entry and editing data were entered on sheet of SPSS ver. 16 (Statistical Package of Social Science), and, Statistical analysis: (Chisquare and analysis of variance) were used to examine group differences.

\section{RESULTS}

The socio-demographic characteristics show that the mean age of patients with psoriasis of both sexes in the sample was 40.91 (standard deviation, SD 14.26) years, while the men: women ration was 2.66: 1. Among the psoriatic patients, $72.6 \%$ were male and $24.6 \%$, were female and $66 \%$ were married versus $34 \%$ were unmarried. Additionally, $68 \%$ of psoriatic patient were occupationally skilled person; $18 \%$ were un-employed; $10 \%$ were professional and $4 \%$ were 
students. Moreover, $56 \%$ of psoriatic patients had educational level of high school or equivalent (diploma); $26 \%$ illiterate Person; $10 \%$ college graduated and $8 \%$ of primary schools levels. One third of patients smoked tobacco (34\%), and of these patients, the median daily tobacco consumption was 16 cigarettes. Fifteen patients (8.7\%) admitted to drinking more than $40 \mathrm{gm}$ of alcohol per day (Table 1).

Table (1): Demographic characteristic data of psoriasis in Egypt sample.

\begin{tabular}{|c|c|c|}
\hline & Number & Percentage \\
\hline $\begin{array}{l}\text { Age in years } \\
\text { (means } \pm \text { SD) }\end{array}$ & $40.91 \pm 14.26$ & \\
\hline $\begin{array}{l}\text { Gender } \\
\text { Male } \\
\text { Female }\end{array}$ & $\begin{array}{c}109 \\
41\end{array}$ & $\begin{array}{l}72.6 \\
27.4\end{array}$ \\
\hline $\begin{array}{l}\text { Marital Status } \\
\text { Unmarried } \\
\text { Married }\end{array}$ & $\begin{array}{l}51 \\
99\end{array}$ & $\begin{array}{l}34 \\
66\end{array}$ \\
\hline $\begin{array}{l}\text { Occupation } \\
\text { Professional } \\
\text { Skilled } \\
\text { Unemployed } \\
\text { Student }\end{array}$ & $\begin{array}{c}15 \\
102 \\
27 \\
6\end{array}$ & $\begin{array}{c}10 \\
68 \\
18 \\
4\end{array}$ \\
\hline $\begin{array}{l}\text { Educational Level } \\
\text { Illiterate } \\
\text { Primary } \\
\text { High school } \\
\text { College level }\end{array}$ & $\begin{array}{l}39 \\
12 \\
84 \\
15\end{array}$ & $\begin{array}{c}26 \\
8 \\
56 \\
10\end{array}$ \\
\hline Tobacco & 51 & 34 \\
\hline $\begin{array}{l}\text { Alcohol } \\
\circ \text { on weekend only } \\
\circ>40 \mathrm{gm} \text { (usually) }\end{array}$ & $\begin{array}{l}30 \\
15\end{array}$ & $\begin{array}{l}20 \\
10\end{array}$ \\
\hline
\end{tabular}


According to Psoriasis Area Severity Index (PASI), 58\% of psoriatic patients reported with moderate severity (>3-15), $28 \%$ with mild severity (0-3) and 14\% with severe cases (>15-72).

A significant relation between gender and the type of psoriasis severity was noticed where $\chi^{2}=31.99$ as shown in table 2 . It appears that severe type of psoriasis was less common (4.59\%) among psoriatic patient men, while it is most common in women (39\%). On the other hand moderate type was the most common among men $(67.88 \%)$ versus $27.52 \%$ for mild severity while no significant difference between mild $\&$ moderate type of psoriasis severity among women recorded as $29.3 \%$ $\& 31.7 \%$, respectively.

Table (2): Co-relation between Psoriasis Area Severity Index (PASI) and gender.

\begin{tabular}{|l|c|c|c|c|}
\hline \multirow{2}{*}{ Psoriasis Severity } & \multicolumn{2}{|c|}{ Gender } & \multicolumn{2}{c|}{ Statistics } \\
\cline { 2 - 3 } & Male & Female & $\chi^{2}$ & P \\
\hline \hline Mild & $30(27.52 \%)$ & $12(29.27 \%)$ & & \\
\hline Moderate & $74(67.88 \%)$ & $13(31.71 \%)$ & \multirow{2}{*}{31.99} & $<0.01$ \\
\hline Sever & $5(4.59 \%)$ & $16(39.01 \%)$ & & \\
\hline Total & $109(72.7 \%)$ & $41(27.3 \%)$ & & \\
\hline
\end{tabular}

A significant relation between occupation and type of psoriasis severity was observed $\chi^{2}=80.28$ as shown in table 3 . It appeared that severe type of psoriasis was more common (73.33\%) among psoriatic patient with professional occupation versus $6.67 \%$ and $20 \%$ for mild $\&$ moderate types of severity, respectively. While Among psoriatic patient with skilled occupation, severe type of psoriasis was less common $(4.90 \%$ ) versus $33.33 \%$ and $61.76 \%$ for mild \& moderate types of 
severity, respectively Moreover, severe types of psoriasis was not encountered between unemployed person, while the majority of psoriatic unemployed persons had moderate severity type $(74.07 \%)$ versus mild type (25.93\%). On the other hand, most of students with psoriasis had severe type $(83.33 \%)$ while moderate type was less encountered (16.67\%).

Table (3): Co-relation between Psoriasis Area Severity Index (PASI) and Occupation.

\begin{tabular}{|c|c|c|c|c|c|c|c|c|c|c|}
\hline \multirow{3}{*}{ Occupation } & \multicolumn{6}{|c|}{ Psoriasis Severity } & \multirow{2}{*}{\multicolumn{2}{|c|}{ Total }} & \multirow{2}{*}{$\chi^{2}$} & \multirow{2}{*}{$\mathbf{P}$} \\
\hline & \multicolumn{2}{|c|}{ Mild } & \multicolumn{2}{|c|}{ Moderate } & \multicolumn{2}{|c|}{ Sever } & & & & \\
\hline & $\mathrm{N}$ & $\%$ & $\mathrm{~N}$ & $\%$ & $\overline{\mathrm{N}}$ & $\%$ & $\mathrm{~N}$ & $\%$ & \multirow{6}{*}{80.28} & \multirow{6}{*}{$<0.01$} \\
\hline Professional & 1 & 6.67 & 3 & 20 & 11 & 73.33 & 15 & 10 & & \\
\hline Skilled & 34 & 33.33 & 63 & 61.76 & 5 & 4.90 & 102 & 68 & & \\
\hline Unemployed & 7 & 25.93 & 20 & 74.07 & 0 & 0 & 27 & 18 & & \\
\hline Student & 0 & & 1 & 16.67 & 5 & 83.33 & 6 & 4 & & \\
\hline Total & 42 & & 87 & & 21 & & 150 & 100 & & \\
\hline
\end{tabular}

A significant relation between educational levels and type of psoriasis severity was noticed where $\chi^{2}=45.33$ as shown in table 4 . It appears that severe type of psoriasis was more common among psoriatic patient with primary and college levels of education recorded as $41.67 \%$ \& $60 \%$, respectively, versus $33.3 \%$ and $25 \%$ (in primary education level) and 13.3 and 26.6 (in college education level) for mild $\&$ moderate types of severity, respectively. On the other hand, moderate type of severity was more encountered among illiterate and high school education level recorded as $56.41 \%$ \& $69 \%$, respectively versus $30.7 \%$ 
and $12.8 \%$ (in illiterate education level) and 28.57 and 2.38 (in high school education level) for mild \& severe types of severity.

Table (4): Co-relation between Psoriasis Area Severity Index (PASI) and education level.

\begin{tabular}{|c|c|c|c|c|c|c|c|c|c|c|}
\hline \multirow{3}{*}{$\begin{array}{l}\text { Education } \\
\text { Level }\end{array}$} & \multicolumn{6}{|c|}{ Psoriasis Severity } & \multirow{2}{*}{\multicolumn{2}{|c|}{ Total }} & \multirow{2}{*}{$\chi^{2}$} & \multirow{2}{*}{$\mathbf{P}$} \\
\hline & \multicolumn{2}{|c|}{ Mild } & \multicolumn{2}{|c|}{ Moderate } & \multicolumn{2}{|c|}{ Sever } & & & & \\
\hline & $\overline{\mathrm{N}}$ & $\%$ & $\overline{\mathrm{N}}$ & $\%$ & $\overline{\mathrm{N}}$ & $\%$ & $\mathrm{~N}$ & $\%$ & \multirow{6}{*}{45.33} & \multirow{6}{*}{$<0.01$} \\
\hline Illiterate & 12 & 30.77 & 22 & 56.41 & 5 & 12.82 & 39 & 26 & & \\
\hline Primary & 4 & 33.33 & 3 & 25 & 5 & 41.67 & 12 & 8 & & \\
\hline $\begin{array}{l}\text { High School/ } \\
\text { Diploma }\end{array}$ & 24 & 28.57 & 58 & 69.05 & 2 & 2.38 & 84 & 56 & & \\
\hline College Level & 2 & 13.33 & 4 & 26.67 & 9 & 60 & 15 & 10 & & \\
\hline Total & 42 & & 87 & & 21 & & 150 & 100 & & \\
\hline
\end{tabular}

Table 5 shows a significant relation between weather condition and type of psoriasis severity was noticed where $\chi^{2}=34.29$. It appears that $69.3 \%$ of psoriatic patients were improved in summer $(\mathrm{p}<0.05)$ and $64 \%$ of patients worsened in winter. During autumn and springs nearly $70 \%$ of patients didn't notice changes in psoriasis signs.

Table (5): Co-relation between Psoriasis Area Severity Index (PASI) and climate.

\begin{tabular}{|c|c|c|c|c|c|c|c|c|c|c|}
\hline \multirow{3}{*}{$\begin{array}{l}\text { Psoriatic } \\
\text { Patients }\end{array}$} & \multicolumn{8}{|c|}{ Weather } & \multirow{3}{*}{$\frac{\chi^{2}}{34.29}$} & \multirow{3}{*}{$\frac{\mathbf{P}}{<0.05}$} \\
\hline & \multicolumn{2}{|c|}{ Summer } & \multicolumn{2}{|c|}{ Winter } & \multicolumn{2}{|c|}{ Autumn } & \multicolumn{2}{|c|}{ Springs } & & \\
\hline & $\mathrm{N}$ & $\%$ & $\mathrm{~N}$ & $\%$ & $\mathrm{~N}$ & $\%$ & $\mathrm{~N}$ & $\%$ & & \\
\hline Stable & 26 & 17.3 & 42 & 28 & 108 & 72 & 106 & $\overline{770.6}$ & & \\
\hline Worsening & 20 & 13.4 & 96 & 64 & 28 & 18.6 & 26 & 17.3 & & \\
\hline Improvements & 104 & 69.3 & 12 & 8 & 14 & 9.3 & 18 & 13 & & \\
\hline
\end{tabular}

Tables $6 \& 7$ show a significant relation between presence of stress and degree of psoriasis severity $\left(\chi^{2}=30.52, \mathrm{P}<0.001\right)$. It appears that 
moderate degree of psoriasis was the most common among psoriatic patient with stress $(45.5 \%)$. Nearly one third (32.6\%) of patients with mild psoriasis without stress where only one fifth (20\%) of mild cases had stress. As regards severe cases of psoriasis only $2-11 \%$ without stress and nearly one third (34.5\%) had stress (table 6).

Table (6): Co-Relation between degree of Psoriasis Area Severity Index (PASI) and presence of stress.

\begin{tabular}{|l|c|c|c|c||}
\hline \multirow{2}{*}{ Psoriasis Severity } & \multicolumn{2}{|c|}{ Stress } & \multicolumn{2}{c|}{ Statistics } \\
\cline { 2 - 4 } & presence & Absence & $\chi^{2}$ & P \\
\hline Mild & $11(20 \%)$ & $31(32.6 \%)$ & & \\
\hline Moderate & $25(45.5 \%)$ & $62(65.3 \%)$ & \multirow{2}{*}{30.52} & $<0.01$ \\
\hline Sever & $19(34.5 \%)$ & $2(2.11 \%)$ & & \\
\hline Total & $55(36.7 \%)$ & $95(63.3 \%)$ & 150 & $100 \%$ \\
\hline
\end{tabular}

On the other hand, there was no significant relation between psoriasis severity degrees and chance of developing psychiatric illness according to The Holmes \& Rahe Scale assessment as the means of stress in mild, moderate and severe types of psoriasis are 110.18 \pm 30.1 ; $110.64 \pm 26.8$ and $97.26 \pm 26.1$ i.e. less than 150 which means a slight risk of psychiatric illness (Table 7). 
Table (7): Co-Relation between degree of Psoriasis Area Severity Index (PASI) and chances of developing psychiatric illness among psoriatic patient with stress according to the Holmes $\&$ Rahe Scale.

\begin{tabular}{|l|c|c|c|}
\hline \multirow{2}{*}{$\begin{array}{c}\text { Psoriasis } \\
\text { Severity }\end{array}$} & $\begin{array}{c}\text { Number of } \\
\text { psoriatic patient } \\
\text { with stress }\end{array}$ & $\begin{array}{c}\text { Mean of Stress } \\
\text { According to the } \\
\text { Holmes \& Rahe Scale }\end{array}$ & $\begin{array}{c}\text { Chance of } \\
\text { developing } \\
\text { psychiatric illness }\end{array}$ \\
\cline { 3 - 4 } & Mean \pm SD (No) & $<\mathbf{1 5 0}$ \\
\hline Mild & $11(20 \%)$ & $110.18 \pm 30.1$ & A slight risk \\
\hline Moderate & $25(45.5 \%)$ & $110.64 \pm 26.8$ & A slight risk \\
\hline Sever & $19(34.5 \%)$ & $97.26 \pm 26.1$ & A slight risk \\
\hline Total & $55(36.7 \%)$ & $107.85 \pm 4$ & A slight risk \\
\hline
\end{tabular}

\section{DISCUSSION}

In this study it was aimed to explore disease characteristics and to assess the relationship between disease characteristics and psoriasisrelated stress and severity a sample of Egyptian people with psoriasis.

The results indicated that the mean age of patients with psoriasis was 40.91 years, this results are consistent with the Egyptian study carried out by El-Moselhy et al. (2012) who recorded that 37.0\%, $44.0 \%$ and $19.0 \%$ of the psoriatic patients with age of onset of $<25,25$ 45 and $\geq 46$ years, respectively. In addition, the finding are in accordance with several studies worldwide where the mean age of Greece psoriatic patients was 43.2 years (Rigopoulos et al., 2010), $25 \pm 16$ years in females, and $28 \pm 15$ years in males (Kundakci, et al., 2002) and most of the Indian psoriatic patients were in their third or fourth decade at the time of presentation (Dogra and Yadav, 2010). 
The present study recorded also that, among the psoriatic patients, $72.6 \%$ were male and $24.6 \%$ were female and the men: women ratio was 2.66:1. The preponderance of male psoriasis patients recorded in the present study was in agreement with that reported by Bedi (1995) (2.5:1) and Kaur et al. (1997) who reported that of total psoriatic patients, $67 \%$ were men and $33 \%$ were women with male to female ratio being (2.03:1). Similar finding have been reported in other studies as in Taiwanese study carried out by Chang et al. (2009) who recorded the prevalence of psoriasis is higher in men than in women and Indian study by Dogra and Yadav (2010) who revealed that prevalence of psoriasis is twice more common in males compared to females. In addition, Greece study carried out by Rigopoulos et al. (2010) recorded that the men to women ratio is $1.8: 1(63.6 \%$ males to $36 \%$ females). However the results are inconsistent with Kavli et al. (1985); Konen et al. (1986); and Kundakci et al. (2002) who found that $61 \%$ of the patients were female, and $39 \%$ were male with the female/male ratio was 1.5 .

Besides, results reported by Raychaudhuri \& Farber (2001); ElMoselhy et al. (2012); Griffiths et al. (2010); Brandrup \& Green (1981); Falk \& Vandbakk, (1993); Gelfand et al. (2005) and Sheffield et al. (2000) found that males and females were equally affected with psoriasis. Also, Mousa et al. (2011), there were no statistically significant differences regarding age, sex, marital status, education, and occupation in Egypt study. This discrepancy could be attributed to the 
observation that the male population under study was suffering from more extensive disease, seeking their treatment in a hospital setting as it was observed that patients with a Body Surface Area (BSA) score 10\% and over have increased frequency of consultations while the frequency of consultations was lower with patients with a lower BSA score (Kundakci et al., 2002).

In this study it was observed that psoriasis is more common between married peoples (66\%) compared with un-married. This finding was in agreement with that reported by Kundakci et al. (2002) who recorded that psoriasis is common between married (65\%), followed by single $(30 \%)$ and less common between divorced or widowed people (5\%). On the reverse, our results is inconsistent with that reported by El-Moselhy et al. (2012), Yosipovitch \& Tang (2002) and Zachariae et al. (2002) who found that single state was significant risk factor of psoriasis and that patients living alone reported more affection than married patients.

Results of this study, as regards marital status, Zachariae et al. (2002) found significant beneficial effects for psoriatic patients to be married (or living with a partner) on both self-reported severity and QOL. In a population-based study of 505 patients with psoriasis, Koo (1996) found that patients with psoriasis reporting more severe symptoms were less likely to be married.

Other demographic variables such as educational background and employment status were found to have a modest influence since $68 \%$ of 
psoriatic patient were occupationally skilled person versus $18 \%$ were un-employed. More than half $(56 \%)$ of psoriatic patients had educational level of high school while $26 \%$ of psoriatic Person was illiterate and $10 \%$ college graduated.

The present study used Psoriasis Area Severity Index (PASI) as a marker of psoriasis severity where $58 \%, 28 \%$ and $14 \%$ of psoriatic patients found with moderate, mild and severe cases. These finding appears to some extent consistent with that reported by Psoriasis Community Canada (2011), where about $65 \%$ of psoriasis patients have mild psoriasis, about $25 \%$ have moderate psoriasis, and about $10 \%$ have severe psoriasis. The difference of the marker used to measure the extent of psoriasis severity may explain the disagreement of our findings with that reported by El-Moselhy et al. (2012) who used Body Surface Area (BSA) as marker for severity and found that $36.0 \%$, $38.0 \%$ and $26.0 \%$ of the cases had mild, moderate and severe forms of disease, respectively. Also, McKenna et al. (2005) found that $30.6 \%$ of cases were severe.

Stress represented the major cause of various self-reported factors leading to exacerbation of psoriasis. Patients with high stress levels report an increased frequency of psoriasis when compared with people with lower stress levels Devrimci-Ozguven et al. (2000). The results recorded a significant relation between presence of stress and degree of psoriasis severity was recorded where moderate degree of psoriasis was the most common among psoriatic patient with stress $(45.5 \%)$ or 
without stress $(65.3 \%)$ while severe type of psoriasis was more common among psoriatic patient with stress (34.5\%) versus mild type $(20 \%)$. The results is consistent with that reported by El-Moselhy et al. (2012) who demonstrated that stress as a suspected risk factor was found in $67.0 \%$ of the patients and Rigopoulos et al. (2010) and Fortune et al. (1998) who reported that more than $60.0 \%$ of their psoriasis patients believed that stress was a principle factor in causation and exacerbation of psoriasis.

In the current study nearly one third (36.7\%) of cases had stress and the remaining two thirds $(63.3 \%)$ had no stress. It is known that in psoriatic patients, psychological stress, by itself, can play a role in exacerbation of psoriasis, and that higher stress reactivity has been associated with the onset of psoriasis at an earlier age (Naldi, et al., 2005). Indeed, $31 \%$ of the patients reported the onset of psoriasis in periods of increased everyday life stress, and in $71 \%$ of patients, psoriasis symptomatology worsened during stressful life episodes (Griffiths and Richards, 2001; and Zachariae, et al., 2004). The importance of stress in psoriasis has been further highlighted, since psychological distress affects treatment outcome in psoriatic patients. For instance, the level of stress may prolong the time taken for psoralen plus UVA (PUVA) to clear the symptoms of psoriasis (Fortune, et al., 2003). Accordingly, stress reduction by stress management, relaxation or cognitive techniques shortened the time to clear psoriasis symptoms by PUVA, and, moreover, improved the clinical severity of psoriasis 
Kabat-Zinn and Wheeler et al. (1998); and Fortune, et al. (2002). An interesting finding is the increase in the catecholamine levels after stress exposure in psoriatic patients (Buske-Kirschbaum, et al., 2006), pointing to a hyper responsive sympathoadrenomedullary system in psoriasis.

The relevance of stress in psoriasis is broadly accepted, however, the underlying mechanisms, of how psychological distress exacerbates or triggers psoriasis, are poorly understood. It is known that psychological stress has the potential to regulate the immune response, and there is emerging evidence that abnormal neuroendocrine response to stress may contribute to the pathogenesis of chronic autoimmune diseases (Jorgensen, et al., 1995).

\section{RECOMMENDATIONS}

1- Holistic medical and psychiatric service for psoriatic patients.

2- Psychological care for psoriatic patients for stress management, psycho-education for prevention of depression and anxiety and dealing with suicidality.

3- Social services and support for the patients and families for better quality of life.

\section{REFERENCES}

Arnold, L. (2005): Dermatology. In: Levenson J.L., ed.: The American Psychiatric Publishing Textbook of Psychosomatic Medicine. 1st ed. Washington, DC: American Psychiatric Publishing; PP 629-646. 
Arnold, L. (2007): Dermatology. In: Levenson J.L., ed.: Essentials of Psychosomatic Medicine. 1st ed. Washington, DC: American Psychiatric Publishing; PP 237-260.

Bedi, T.R. (1995): Clinical profile of psoriasis in North India. Indian J Dermatol Venereol Leprol; 61:202-5.

Bell, L.M., Sedlack, R., Beard, C.M., Perry, H.O., Michet, C.J. and Kurland, L.T. (1991): Incidence of psoriasis in Rochester, Minn, 1980-1983. Arch Dermatol 127:11841187.

Brandrup, F. and Green, A. (1981): The prevalence of psoriasis in Denmark. Acta Derm Venereol; 61:344-346.

Buske-Kirschbaum, A.; Ebrecht, M.; Kern, S. and Hellhammer, D.H. (2006): Endocrine stress responses in TH1-mediated chronic inflammatory skin disease (psoriasis vulgaris) - do they parallel stress-induced endocrine changes in TH2mediated inflammatory dermatoses (atopic dermatitis)? Psychoneuroendocrinology, 31(4):439-46.

Chang, Yun-Ting; Chen, Tzeng-Ji; Liu, Pei-Chi; Chen, Yu-Chun; Chen, Yi-Ju, Huang, Yu-Lin; Jaw-Shyang, Jih; Chen, ChihChiang; Lee, Ding-Dar; Wang, Wen-Jen; Lin, Ming-Wei and Liu, Han-Nan (2009): Epidemiological Study of Psoriasis in the National Health Insurance Database in Taiwan Acta Derm Venereol; 89:262-266.

Devrimci-Ozguven, H.; Kundakci, T.N.; Kumbasar, H. and Boyvat, A. (2000): The depression, anxiety, life satisfaction and affective expression levels in psoriasis patients. J Eur Acad Dermatol Venereol.; 14(4):267-271.

Dogra, S. and Yadav, S. (2010): Psoriasis in India: Prevalence and pattern. Indian Journal of Dermatology, Venereology and Ieprology (IJDVL); 76(6): 595-601

Dunna, S.F. and Finlay, A.Y. (1989): Psoriasis: improvement during and worsening after pregnancy. $\mathrm{Br} \mathrm{J}$ Dermatol.; 120(4):584. 
El-Moselhy, Essam, A.; Nada, Ibrahim, S.; Khalifa, Hamed, O.; Hassan, Hassan, M. and Abd-Alrahman, Throwt, M. (2012): Psoriasis and Psoriatic Arthritis: Characteristics and risk factors among adult patients in Egypt. The Egyptian Journal of Hospital Medicine, 47:301-320.

Eyre, R.W. and Krueger, G.G. (1982): Response to injury of skin involved and uninvolved with psoriasis and its relation to disease activity: Koebner and 'reverse' Koebner. Br J Dermatol; 106:153-9.

Falk, E.S. and Vandbakk, O. (1993): Prevalence of psoriasis in a Norwegian Lapp population. Acta Derm Venereol Suppl (Stockh); 182: 6-9.

Fortune, D.G.; Richards, H.L.; Main, C.J. and Griffiths, C.E. (1998): What patients with psoriasis believe about their condition. J Am Acad Dermatol; 39:196-201.

Fortune, D.G.; Richards, H.L.; Kirby, B.; Bowcock, S.; Main, C.J. and Griffiths, C.E. (2002): A cognitive-behavioural symptom management programme as an adjunct in psoriasis therapy. Br J Dermatol; 146:458-465.

Fortune, D.G.; Richards, H.L.; Kirby, B.; McElhone, K.; Markham, T.; Rogers, S.; Main, C.J. and Griffiths, C.E. (2003): "Psychological distress impairs clearance of psoriasis in patients treated with photochemotherapy," Archives of Dermatology, 139(6):752-756.

Gelfand, J.M.; Weinstein, R.; Porter, S.B.; Neimann, A.L.; Berlin, J.A. and Margolis, D.J. (2005): Prevalence and treatment of psoriasis in the United Kingdom: a population-based study. Arch Dermatol; 141:1537-41.

Griffiths, E.M. and Richards, H.L. (2001): "Psychological influences in psoriasis," Clinical and Experimental Dermatology, 26(4):338-342. 
Griffiths, C.E.M. (2010): Management of psoriasis in Pregnancy: Time to deliver. British Journal of Dermatology, 163:235-237.

Gupta, M.A.; Gupta, A.K.; Schork, N.J. and Ellis, C.N. (1994): Depression modulates pruritus perception: a study of pruritus in psoriasis, atopic dermatitis, and chronic idiopathic urticaria. Psychosom Med.; 56(1):36-40.

Jorgensen, C.; Bressot, N.; Bologna, C. and Sany, J. (1995): "Dysregulation of the hypothalamo-pituitary axis in rheumatoid arthritis." J Rheumatol, 22(10):1829-33.

Kabat-Zinn, J; Wheeler, E; Light, T; Skillings, A; Scharf, M.J.; Cropley, T.G.; Hosmer, D.; and Bernad, J.D. (1998): "Influence of a mindfulness meditation-based stress reduction intervention on rates of skin clearing in patients with moderate to severe psoriasis undergoing phototherapy (UVB) and photochemotherapy (PUVA)." Psychosom Med, 60 (5):625-32.

Kaur, I.; Handa, S. and Kumar, B. (1997): Natural history of psoriasis: a study from the Indian subcontinent. J Dermatol.; 24:2304.

Kavli, G. \& Forde, O.H.; Arnessen, E. and Stenvold S.E. (1985): Psoriasis: familial predisposition and environmental factors. BMJ; 291:999-1000.

Knnen, M.; Torppa, J. and Lassus, A. (1986): An epidemiological survey of psoriasis in the Greater Helsinki Area. Acta Derm Venereol; 124:1-10.

Koo, J. (1996): Population-based epidemiologic study of psoriasis with emphasis on quality of life assessment. Psychodermatology; 14:485-96.

Kreft, S; Kreft, M; Resman, A, Marko; P.B. and Kreft, K.Z (2006): Computer-aided measurement of psoriatic lesion area in a multicenter clinical trial - Comparison to physician's estimations. J. Dematol. Sci. (Amst.); 44(1):21-7. 
Kundakci, N.; Türsen, Ü.; Babiker, M.O.A. and Gürgey, E. (2002): The evaluation of the sociodemographic and clinical features of Turkish psoriasis patients. International Journal of Dermatology; 41(4):220-224.

McKenna, S.; Lebwohl, M. and Kahler, K. (2005): Development of the US PSORIQoL: A psoriasis-specific measure of quality of life. Int J Dermatol, 44:462-9.

Mousaa, Abd El Latif; Fatma, Zaherb; Hesham, Abd El Moati; Mohammed, Ezzat; Amina, Akmal; Mostafa, Kamala and Heba, Fathya (2011): Comorbid psychiatric symptoms in patients with psoriasis. Middle East Current Psychiatry; $18: 78-85$

Naldi, L.; Chatenoud, L.; Linder, D.; Vellón Fortina, A.; Peserito, A. and Virgili, A.R. (2005): Cigarette smoking, body mass index, and stressful life events as risk factors of psoriasis: results from an italian case-control study. J Invest Dermatol.; 125:61-72.

Okasha, A.; Sadek, A.; Lotaief, F. and Bishri, Z. (1981): The Social Readjustment Rating Questionnaire A study of Egyptians. Egyptian Journal of Psychiatry, 4(2):273-283.

Psoriasis Community Canada (2011): Canadian Association of Psoriasis Patients Canadian Skin Patient Alliance.

Raychaudhuri, S.P. and Farber, E.M. (2001): The prevalence of psoriasis in the world. J Eur Acad Dermatol Venereol; $15: 16-17$.

Rigopoulos, D.; Gregoriou, S.; Katrinaki, A.; Korfitis, C.; Larios, G.; Stamou, C.; Mourellou, O.; Petridis, A.; Rallis, E.; Sotiriadis, D.; Katsambas, A.D. and Antoniou, C. (2010): Characteristics of psoriasis in Greece: an epidemiological study of a population in a sunny Mediterranean climate. Eur J Dermatol; 20(2):189-95.

Ros, A.M. and Eklund, G. (1987): Photosensitive psoriasis. An epidemiologic study. J Am Acad Dermatol; 17(5):752-8. 
Sheffield, D.; Biles, P.L.; Orom, H.; Maixner, W. and Sheps, D. (2000): Race and sex differences in cutaneous pain perception. Psychosom Med; 62:517-23.

Tervaert, W.C. and Esseveld, H.A. (1970): Study of the incidence of haemolytic streptococci in the throat in patients with psoriasis vulgaris, with reference to their role in the pathogenesis of the disease. Dermatologica; 140:282-290.

Telfer, N.R.; Chalmers, R.J.; Whale, K. and Colman, G. (1992): The role of streptococcal infection in the initiation of guttate psoriasis. Arch Dermatol; 128:39-42.

Yosipovitch, G. and Tang, M.B. (2002): Practical management of psoriasis in the elderly: epidemiology, clinical aspects, quality of life, patient education and treatment options. Drugs Aging 19:847-863

Zachariae, R.; Zachariae, H.; Blomqvist, K.; Davidson, S.; Molin, L.; Mork, C. and Sigurgeirsson, B. (2002): Quality of life in 6,479 Nordic patients with psoriasis. Br J Dermatol, 146:1006-16.

Zachariae, R.; Zachariae, H.; Blomqvist, K.; Davidsson, S.; Molin, L. and Mørk, C. (2004): Self-reported stress reactivity and psoriasis-related stress of Nordic psoriasis sufferers. J Eur Acad Dermatol Venereol; 18(1):27-36. 


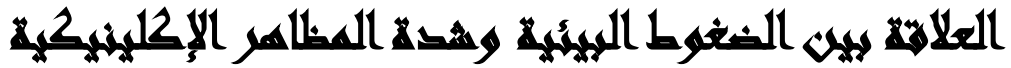

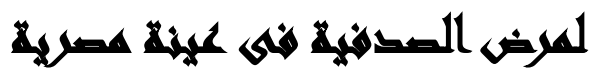

$[\vee]$

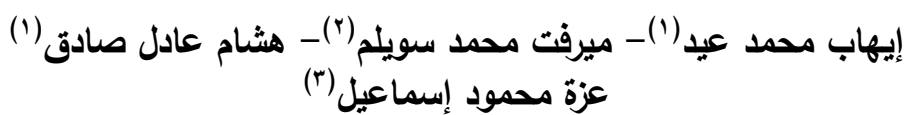

( ) كلية الطب، جامعة عين شمس r) كلية الطب، جامعة الأزهر (بنات) ؟) وزارة الصحة (r)

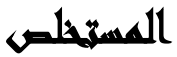

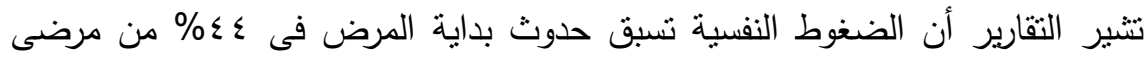

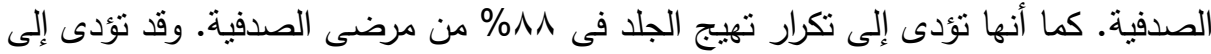

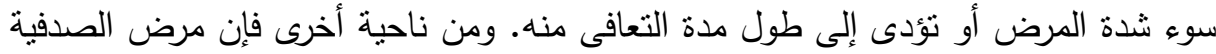

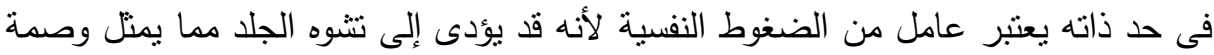

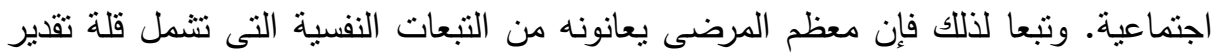

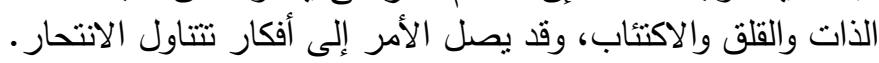

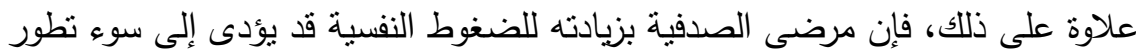

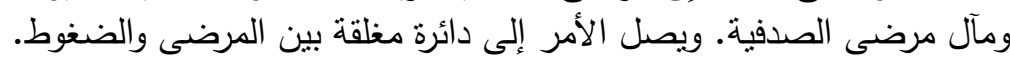

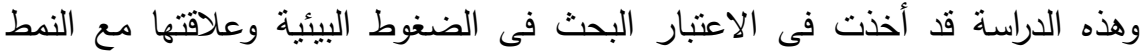
الإكلينيكى وشدته فى مرضى الصند فيدفية فيى عينة مصرية.

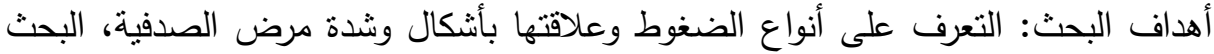

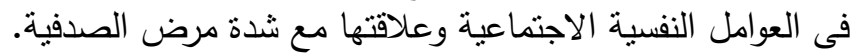
في الدراسة الحالية: تم جمع عينة من ـ10 مريض معاعلة من عيادة الأمراض الجلدية التابعة لمستثفيات وزارة الصحة والجامعات.

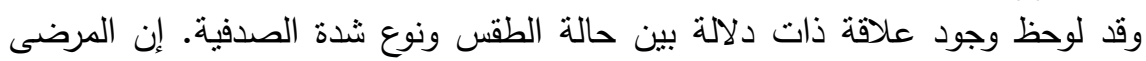

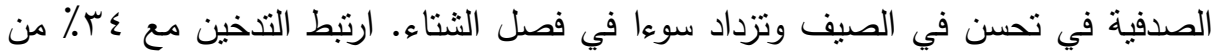

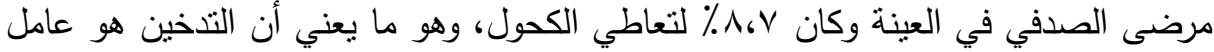
خطر لمرض الصدفية، ولكن الكحول وتعاطي المخدرات فقط يزيد سوء لهان حالة الصدفية.

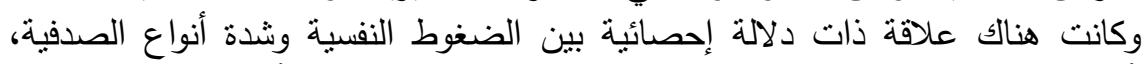

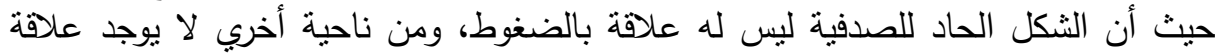

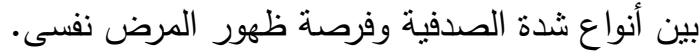


وكان متوسط العمر للصدفية •ـ عاما. كان نوع شديد من الصدفية أقل شيوعا بين

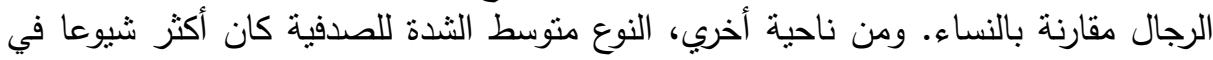

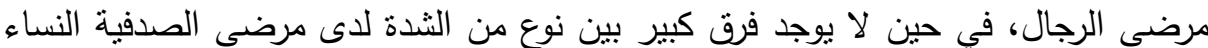

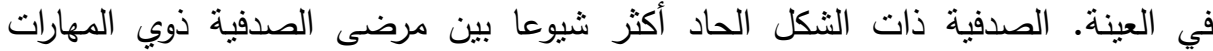
المهنية، طلبة الابتدائي وطلبة الجامعة. 